\title{
Image Compression based on Fixed Predictor Multiresolution Thresholding of Linear Polynomial Nearlossless Techniques
}

Ghadah Al-Khafaji

Dept. of Computer Science, Baghdad

University, College of Science.

\section{Shaymaa Fadhil}

Dept. of Computer Science, Baghdad

University, College of Science.

Recived : $317 \backslash 2017$

Revised : 2517\2017

Accepted : $2118 \backslash 2017$

\begin{abstract}
Image compression is a serious issue in computer storage and transmission, that simply makes efficient use of redundancy embedded within an image itself; in addition, it may exploit human vision or perception limitations to reduce the imperceivable information

Polynomial coding is a modern image compression technique based on modelling concept to remove the spatial redundancy embedded within the image effectively that composed of two parts, the mathematical model and the residual.

In this paper, two stages proposed technqies adopted, that starts by utilizing the lossy predictor model along with multiresolution base and thresholding techniques corresponding to first stage. Latter by incorporating the near lossless compression scheme of first stage that corresponding to second stage.
\end{abstract}

The tested results shown are promising in both two stages, that implicilty enhanced the performance of traditional polynomial model in terms of compression ratio, and preresving image quality.

\section{Key words: Image compression, fixed predictor, wavelet transform, linear polynomial and nearlossless techniques.}




\section{Introduction}

Today, people sharing the information and communicate with each other easily, cheaply and instantly via the realm of the social media communications tools using the smart phones, tables and computers, where the images become the essence, especially in occasions (i.e., Eids, Christmas time and Birthdays), news, marketing, entertainment, but unfortunately these images required huge size that implicitly consumed large size of bytes where redundancy presents, so the compression is the optimal solution where the redundancy removed efficiently [1].

Reducing the image data size is referred to as image compression, that generally represents the significant image information compactly with smaller size of bytes while losing the insignificant image information, which is called redundancy [1].

Image compression techniques is basically fall into two categories: lossless and lossy depending on the redundancy type(s)exploited, where lossless also called information preserving or error free techniques, in which the image compressed without losing information, and are based on the utilization of statistical redundancy alone such as Huffman coding, Arithmetic coding, and Lempel-Ziv algorithm, while lossy which remove content from the image, which degrades the compressed image quality, and are based on the utilization of psycho-visual redundancy, either solely or combined with statistical redundancy such as such as vector quantization, fractal, and JPEG [2].

The fixed predictor is related to eliminates the highly dependency (correlation) between image pixels, where most of the similarity embedded in an image neighbours [1]. On the other hand, there's an increase role of utilization wavelet in image compression due to the fact that it provides high image quality with high compression ratios, due to exploits both the spatial and frequency correlation of data by contractions and translations of mother wavelet on the input data, supports the multi- resolution analysis of data and symmetric nature [3]. While, polynomial coding is one of the modern image compression techniques remains in development adopted within the last few years, based on the modeling concept of mathematical base that basically composed of two parts of deterministic part (i.e., mathematical function) and stochastic part (i.e., error), that implicitly means, create an approximated image to the original one using the adopted mathematical model, and find the error or the residual image as the difference between the original and the approximated image [4]. Lastly, the near lossless base, corresponding to allowed error tolerance, in which no pixel is changed in magnitude by more than $\delta$ gray levels compared with the origin [5].

This paper is concerned with improving the polynomial techniques performance of linear base, using fixed predictor and multiresolution thresholding techniques of two stages near lossless coder. The rest of the paper is organized as follows, section 2 contains comprehensive clarification of the proposed system; the results of the proposed system and the conclusions are given in sections 3 and 4 respectively.

\section{Proposed System}

The proposed technique composed of two stages, starting by the lossy fixed predictor of wavelet thresholding techniques, followed by the near lossless coder, which discussed extensively in the following steps:

Stage 1: this stage is concerned with utilizing fixed predictor of difference base between the pixel and its neighbours', then subsequently implemented the wavelet transform of thresholding quantization process (i.e., soft) of quadrants using the following sub steps that depicted clearly in figure (1). 
Ghadah .K / Shaymaa .F

1- Load the original uncompressed gray image $I$ of $B M P$ format of size $N \times N$.

2-Use the simple fixed predictor to remove the redundancy from image $I$, the exploited predictor is of one neighbour causal dependency form of one dimension structure, such as [1]:

$$
F p(i, j)=I(i, j)-I(i-1, j)
$$

Where $F p$ is the fixed predictor image that eliminate correlation embedding by keeping only the differentiations between the current pixel value and the one in the preceding row, where the first row from the image $I$ preserved to construct the image back.

3- Perform the wavelet transform of fixed predicted image above $F p$ that decomposed into four quadrants of approximation and detail sub bands (i.e., $F p_{\text {LowLow }} F p_{\text {Low High }}, F p_{\text {High Low }}$ and $\left.F p_{\text {High High }}\right)$ respectively.

4- For the approximation subband, apply the traditional linear polynomial coding technique that based on partitioning the $F p_{\text {Low Low }}$ image into fixed blocks of size $n \times n$ and computing the coefficients of each block, followed by creating the predicted image and lastly finding the residual image, according to equations (211) [6].

$$
\begin{aligned}
& a_{0}=\frac{1}{n \times n} \sum_{i=0}^{n-1} \sum_{j=0}^{n-1} F p_{\text {Low }} \operatorname{Low}^{(i, j) \ldots \ldots \ldots \ldots . . .(2)} \\
& a_{1}=\frac{\sum_{i=0}^{n-1} \sum_{j=0}^{n-1} F p \operatorname{LowLow}^{(i, j) \times\left(j-x_{C}\right)}}{\sum_{i=0}^{n-1} \sum_{j=0}^{n-1}\left(j-x_{C}\right)^{2}} \ldots \ldots \ldots \ldots \ldots \ldots \ldots \ldots .(3)
\end{aligned}
$$

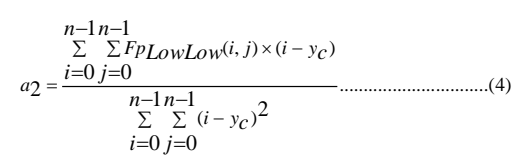$$
x c=y c=\frac{n-1}{2} .
$$

$$
\begin{aligned}
& a_{0} Q=\operatorname{round}\left(\frac{a_{0}}{Q S_{a 0}}\right) \rightarrow a_{0} D=a_{0} Q \times Q S_{a 0} \ldots \ldots \ldots .(6) \\
& a_{1} Q=\operatorname{round}\left(\frac{a_{1}}{Q S_{a 1}}\right) \rightarrow a_{1} D=a_{1} Q \times Q S_{a 1} \ldots \ldots \ldots .(7) \\
& a_{2} Q=\operatorname{round}\left(\frac{a_{2}}{Q S_{a 2}}\right) \rightarrow a_{2} D=a_{2} Q \times Q S_{a 2} \ldots \ldots \ldots(8)
\end{aligned}
$$

$$
\tilde{F} p_{L o w L o w}=a_{0} D+a_{1} D\left(j-x_{C}\right)+a_{2} D\left(i-y_{c}\right)
$$

$\operatorname{Re} s(i, j)=F p \operatorname{LowLow}^{(i, j)-\tilde{F} p} \operatorname{LowLow}^{(i, j)}$

$\operatorname{Re} s Q=\operatorname{round}\left(\frac{\operatorname{Re} s}{Q S \operatorname{Re} s}\right) \rightarrow \operatorname{Re} s D=\operatorname{Re} s Q \times Q S \operatorname{Re}$

The symbol encoder techniques exploited to remove the rest of redundancy that embedded between the quantized values of the residual and the polynomial coefficients using Huffman techniques.

5- For the details sub bands $\left(F p_{\text {LowHigh }}\right.$ $F p_{\text {HighLow }}$ and $\left.F p_{\text {HighHigh }}\right)$ use the soft thresholding technique, where each quadrant is quantized using different quantization threshold value according to equations below [7].

Threshold ${ }_{F p}$ LowHigh $=\frac{\text { Number of Zeros of } \mathrm{Fp} \text { LowHighdecomposition }}{\text { Number of Coefficiert of } \mathrm{Fp} \text { LowHighdecomposition }}$

Threshold $_{\text {Fp HighLow }}=\frac{\text { Number of Zeros of } \mathrm{Fp} \text { HighLowdecomposition }}{\text { Number of Coefficiert of } \mathrm{Fp} \text { HighLowdecomposition }}$

Threshold $_{\text {Fp HighHigh }}=\frac{\text { Number of Zeros of } \mathrm{Fp} \text { HighHighdecomposition }}{\text { Number of Coefficiert of Fp HighHighdecomposition }}$. 
Ghadah .K / Shaymaa .F

Then the soft thresholding techniques can be summarized such as [4]

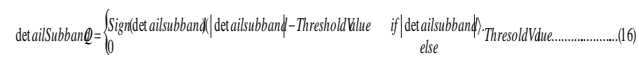

6- To reconstruct the decoded or compressed image $\hat{I}$, the decoder first reconstruct the approximation subband by adding the predicted image to the dequantized residual image (eq. 17), then utilized inverse wavelet transform of the quadrants sub bands $\hat{F} p$ that added to the first known row image to build the compressed decoded image $\hat{I}$, such as:

$\hat{F} p_{\text {LowLow }}(i, j)=\tilde{F} p_{\text {Low Low }}(i, j)+\operatorname{Res} D(i, j)$

$\hat{I}(i, j)=\hat{F} p(i, j)+I(i-1, j)$

Stage 2: this stage is the complementary stage of the proposed system that utilized the near lossless base, in which no pixel is changed in magnitude by more than $\delta$ gray levels compared with the origin, where $\delta$ is a nonnegative integer indicating the error tolerance [5]. The idea relies on exploiting another coder stage as a difference between the lossy reconstruction image of first stage $(\hat{I})$ and the original image $(I)$, that quantize uniformly to guarantee the maximum error no longer than $\delta$, where the following sub steps adopted [5], also figure (2) illustrate the idea clearly.

1- Find the difference between the lossy compressed image and the original one.

$e=\hat{I}-I$
2- quantize/dequantize the difference uniformly as follows to guarantee the maximum error no longer than $\delta$.

$$
\begin{aligned}
& e_{q-i d x=\operatorname{round}}\left(\frac{e+\delta}{2 \delta+l}\right) \\
& e_{q-i d x=\operatorname{round}}\left(\frac{e-\delta}{2 \delta+l}\right)
\end{aligned}
$$

Where $l$ is the quantization index that is generated as follows for each pixel [5]:

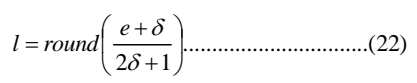

Where $e$ is the error (difference) pixel value, and then encodes the compressed information. The dequantized error image reconstructed as [5].

$\hat{e}=l \times(2 \delta+1)$.

3- Reconstruct the decoded (compressed) image according to equation below.

$\hat{I}_{n e a r}=\hat{I}+\hat{e}$

\section{Expermental Results}

In order to test the performance of the traditional polynomial coding and comparing it with the two stages proposed system, three well-known standard images adopted (see figure (3) for an overview), all images of 256 gray levels (8bits/pixel) of size $256 \times 256$, also the compression ratio utilized along with the objective fidelity criteria of PSNR measure.

CompressionRatio $=\frac{\text { Size of Original Image }}{\text { Size of Compressed Information }}$

$P S N R=10 \cdot \log 10\left[\frac{(255)^{2}}{\frac{1}{N \times N} \sum_{x=0}^{N-1 N-1}\left[(\operatorname{decoded}(x, y)-\operatorname{original}(x, y)]^{2}\right.}\right]$ 


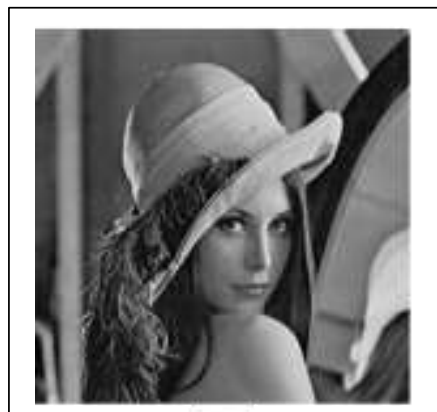

a

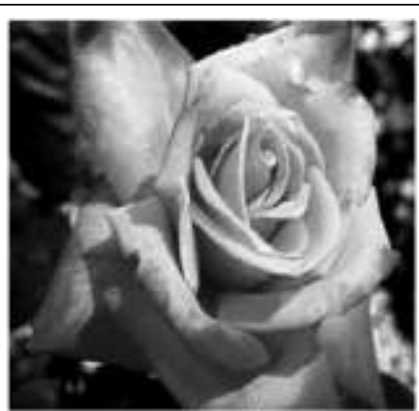

b

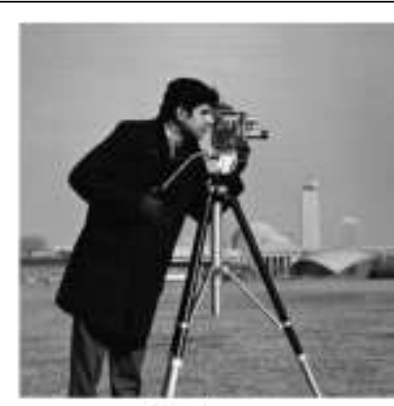

c

Fig. (3): Overview of the tested images (a) Lena image, (b) Rose image and (c) Camera image, all images of size $256 \times 256$, gray scale images.

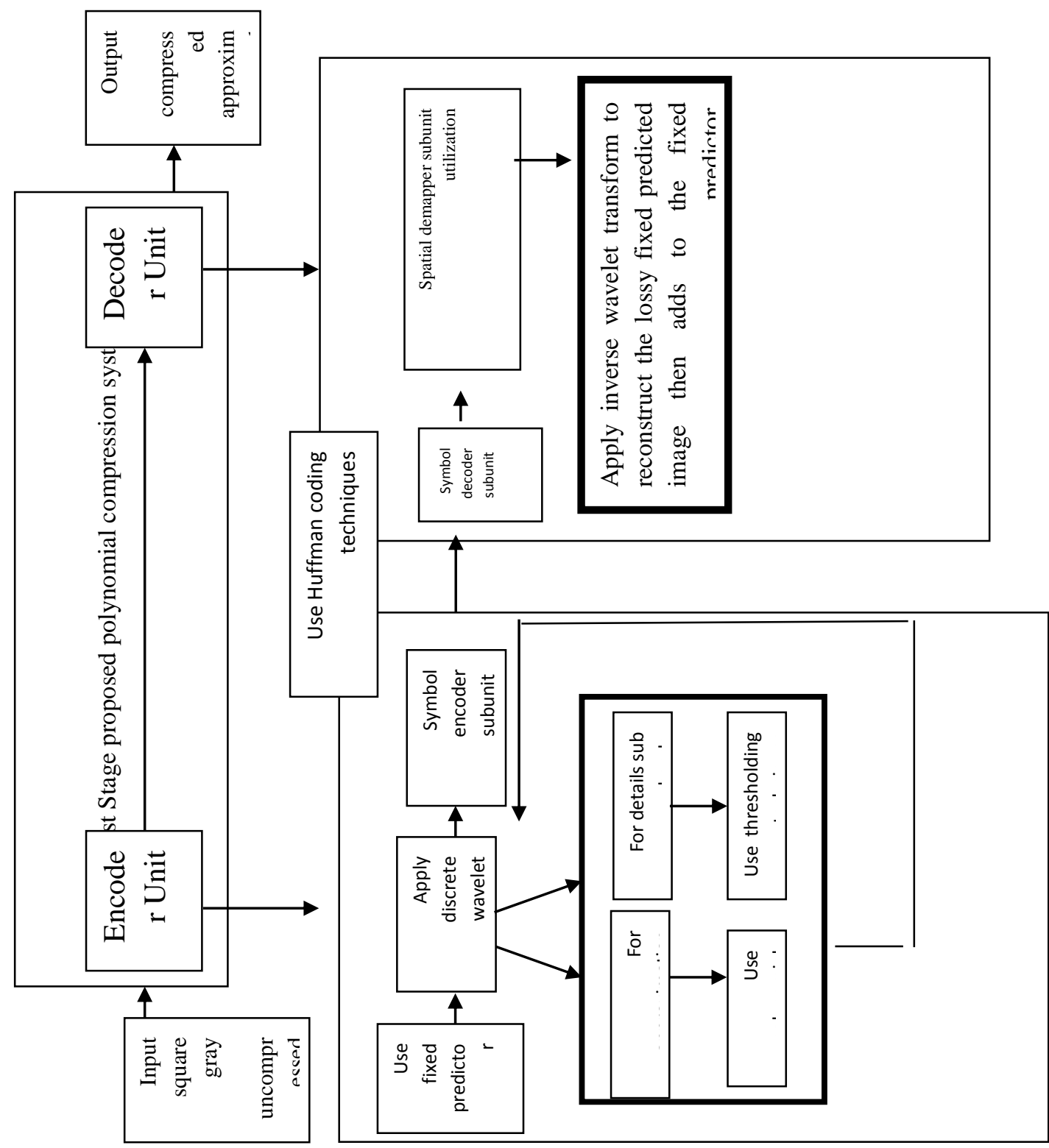

ह 


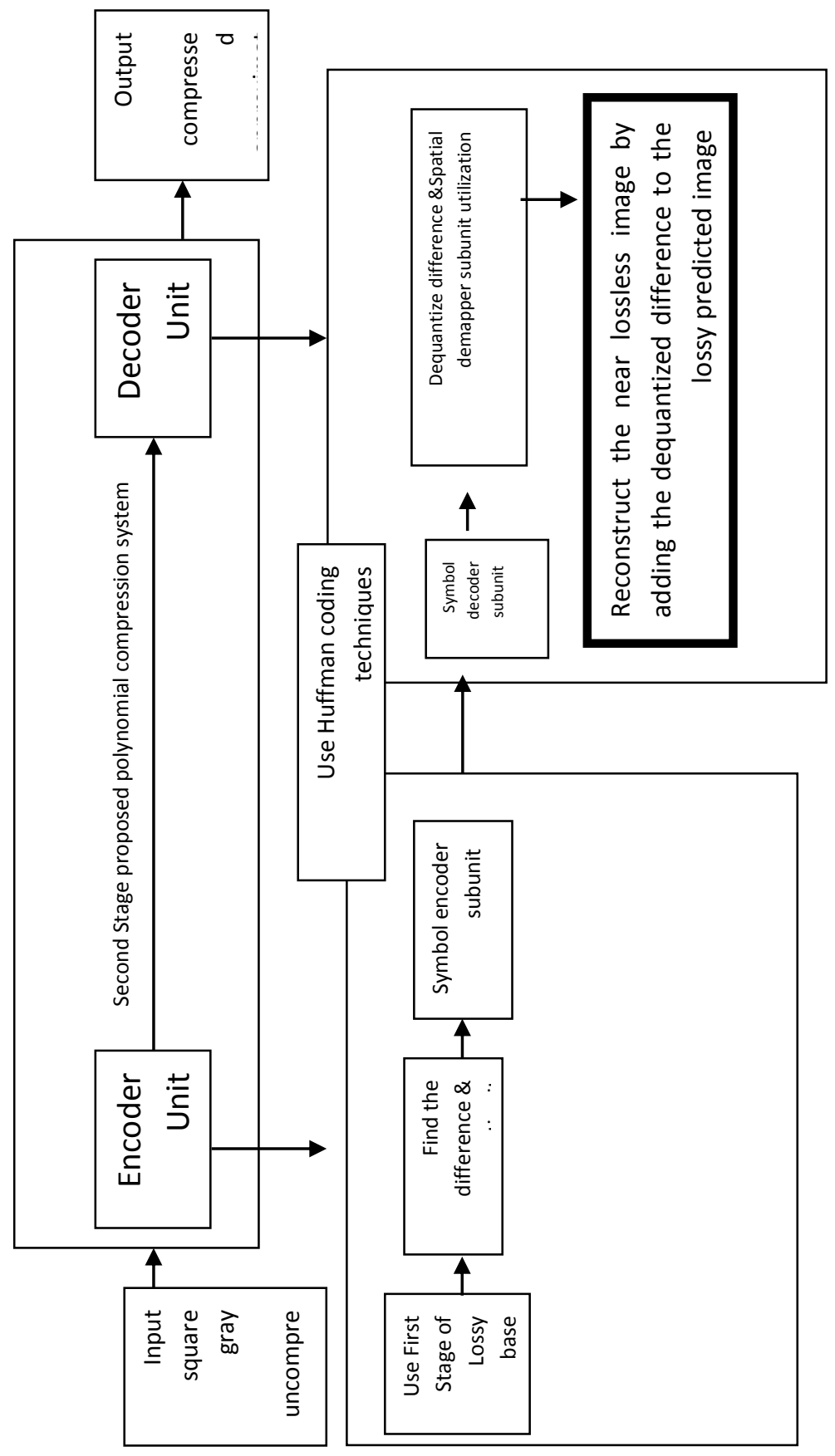

The experimental results of traditional polynomial coding are listed in table (1) of the tested images, that clearly showed that the quality of the decoded image affected by the quantization step value, that implicitly affect the compression ratio. Certainly, a higher compression ratio corresponds to higher degradation of the image (i.e., high distortion levels). Inversely, low compression ratios mean high quality, where there is a trade-off between the desired compression ratio and the desired quality. 
Table (1): The performance of traditional polynomial coding for the three tested images.

\begin{tabular}{|c|c|c|c|c|c|c|}
\hline \multicolumn{7}{|c|}{ Traditional Polynomial coding } \\
\hline \multirow[t]{2}{*}{$\begin{array}{l}\text { Tested } \\
\text { Images }\end{array}$} & \multicolumn{2}{|c|}{$\begin{array}{c}Q a_{0}=1 \quad a_{1}=2 \quad Q_{2}=2 \\
Q_{\text {Res }}=20\end{array}$} & \multicolumn{2}{|c|}{$\begin{array}{c}Q a_{0}=1 \quad Q a_{1}=2 \quad Q a_{2}=2 \\
Q_{\text {Res }}=50\end{array}$} & \multicolumn{2}{|c|}{$\begin{array}{c}Q a_{0}=1 \quad Q a_{1}=2 \quad Q a_{2}=2 \\
Q_{\text {Res }}=70\end{array}$} \\
\hline & CR & PSNR & CR & PSNR & CR & PSNR \\
\hline Lena & 7.0567 & 34.9235 & 9.0407 & 30.0366 & 9.6306 & 28.5598 \\
\hline Rose & 8.0402 & 36.3577 & 9.8402 & 32.5447 & 10.2113 & 31.7404 \\
\hline Cameraman & 7.0567 & 34.9235 & 9.0407 & 30.0366 & 10.6306 & 28.5598 \\
\hline
\end{tabular}

In order to improve the performance of the traditional polynomial coding, two stages have been adopted, the first one based on utilizing the fixed predictor of wavelet transform that exploited both the traditional polynomial coding of approximation subband and used the soft thresholding of details sub bands.

The results shown in table (2) and figure (4 a,b,c) illustrates that about twice on average compression ratio is achieved with high image quality compared to the traditional polynomial coding. The main reason of the improving of image quality in this stage (first stage), is due to utilizing of fixed predictor that preserver the image information as much as possible before compressed it. At the same time, the compression ratio improved, due to less correlation between image neighbouring pixels, where keeping only the difference values and leaving only details around the edges (i.e., small details ignored according to threshold value).

Table (2): The performance of first stage proposed system for the three tested images.

\begin{tabular}{|c|c|c|c|c|c|c|}
\hline \multicolumn{7}{|c|}{ Lossy Fixed Predictor Wavelet Thresholding Techniques } \\
\hline \multirow[t]{2}{*}{$\begin{array}{l}\text { Tested } \\
\text { Images }\end{array}$} & \multicolumn{2}{|c|}{$\begin{array}{c}Q a_{0}=1 \quad a_{1}=2 \quad Q a_{2}=2 \\
Q_{\text {Res }}=20\end{array}$} & \multicolumn{2}{|c|}{$\begin{array}{c}Q a_{0}=1 \quad a_{1}=2 \quad Q a_{2}=2 \\
Q_{\text {Res }}=50\end{array}$} & \multicolumn{2}{|c|}{$\begin{array}{c}Q a_{0}=1 \quad a_{1}=2 \quad Q a_{2}=2 \\
Q_{\text {Res }}=70\end{array}$} \\
\hline & CR & PSNR & $\mathbf{C R}$ & PSNR & CR & PSNR \\
\hline Lena & 13.5826 & 34.2438 & 17.3651 & 31.6869 & 18.7621 & 30.2856 \\
\hline Rose & 10.1811 & 41.5233 & 12.0272 & 37.8743 & 12.6274 & 36.4312 \\
\hline Cameraman & 11.9112 & 36.9732 & 13.8965 & 35.3923 & 14.6942 & 34.2736 \\
\hline
\end{tabular}




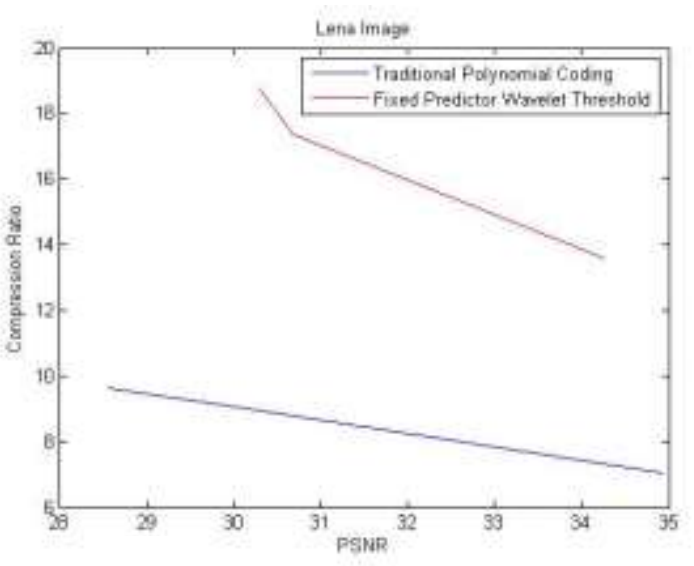

a

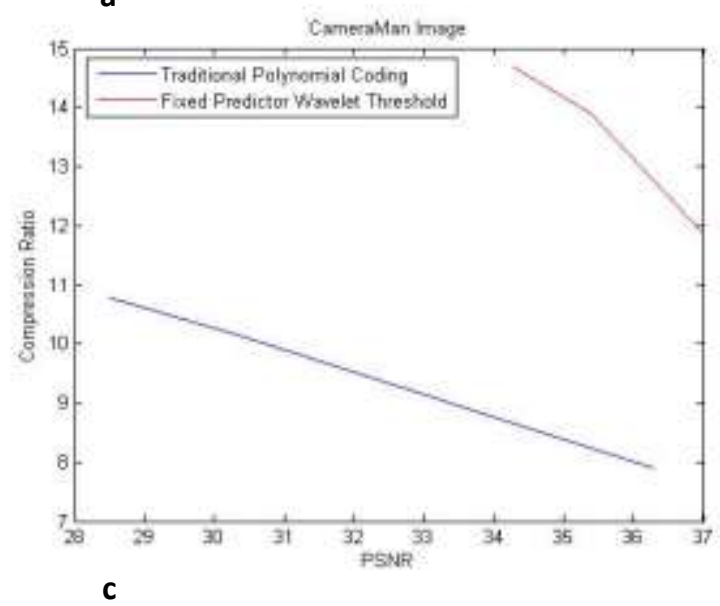

The last experiments of two stage techniques where results shown in table(3), tested the exploited the near lossless base concept, where the results illustrate the

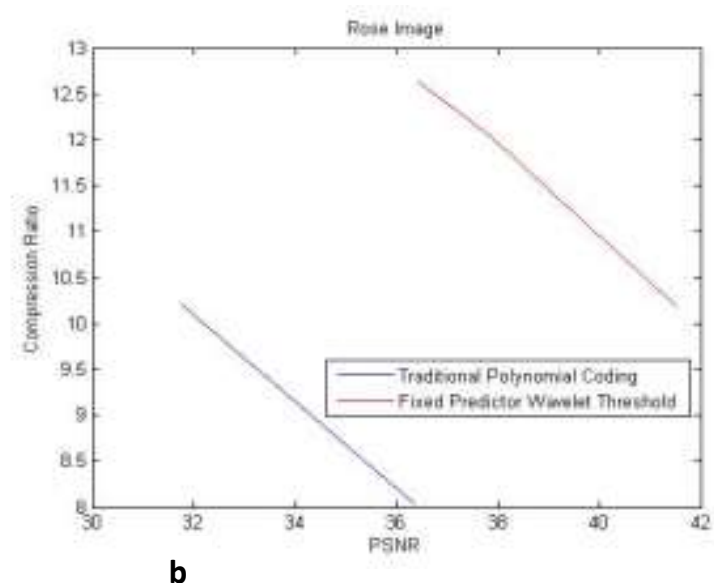

Fig (4): PSNR versus the compression ratio of traditional and first stage adaptive techniques for (a) Lena, (b) Rose and (c) Cameraman images.

Table (3): The performance of second stage proposed system for the three tested images.

\begin{tabular}{|c|c|c|c|c|c|c|c|}
\hline \multicolumn{8}{|c|}{ Using Soft Thresholding Technique using block sizes of $4 \times 4$} \\
\hline & \multicolumn{2}{|c|}{$\begin{array}{c}\text { Traditional } \\
\text { Polynomial coding } \\
\text { using } Q a_{0}=1 \quad Q a_{1}=2 \\
Q a_{2}=2 Q_{R e s}=20\end{array}$} & \multicolumn{2}{|c|}{$\begin{array}{c}\text { Stage1 using } Q a_{0}=1 \\
Q a_{1}=2 \mathrm{Qa}_{2}=2 \mathrm{QRes}_{\mathrm{Res}}=20 \\
\mathrm{LH}_{T h r}=21 \mathrm{HL}_{T h r}=36 \\
\mathrm{HH}_{T h r}=32\end{array}$} & \multicolumn{3}{|c|}{$\begin{array}{c}\text { Stage } 2 \text { using } Q a_{0}=1 \quad Q a_{1}=2 \\
Q a_{2}=2 Q_{R e s}=20 L_{T h r}=21 \\
H L_{T h r}=36 \text { and } H H_{T h r}=32\end{array}$} \\
\hline $\begin{array}{l}\text { Tested } \\
\text { images }\end{array}$ & $\mathbf{C R}$ & PSNR & $\mathbf{C R}$ & PSNR & $\delta$ & $\mathbf{C R}$ & PSNR \\
\hline \multirow[t]{3}{*}{ Lena } & \multirow[t]{3}{*}{7.0567} & \multirow[t]{3}{*}{34.9235} & \multirow[t]{3}{*}{13.5826} & \multirow[t]{3}{*}{34.2438} & $=0 \delta$ & 12.2681 & 58.7706 \\
\hline & & & & & $=1 \delta$ & 12.4215 & 45.68397 \\
\hline & & & & & $=2 \delta$ & 12.6274 & 40.2718 \\
\hline \multirow[t]{3}{*}{ Rose } & \multirow[t]{3}{*}{8.0402} & \multirow[t]{3}{*}{36.3577} & \multirow[t]{3}{*}{10.1811} & \multirow[t]{3}{*}{41.5233} & $=0 \delta$ & 9.5381 & 60.9716 \\
\hline & & & & & $=1 \delta$ & 9.8148 & 51.8887 \\
\hline & & & & & $=2 \delta$ & 10.0723 & 42.4460 \\
\hline \multirow[t]{3}{*}{ Cameraman } & \multirow[t]{3}{*}{7.8997} & \multirow[t]{3}{*}{36.2931} & \multirow[t]{3}{*}{11.9113} & \multirow[t]{3}{*}{36.9732} & $=0 \delta$ & 10.9923 & 59.0591 \\
\hline & & & & & $=1 \delta$ & 11.2277 & 50.6976 \\
\hline & & & & & $=2 \delta$ & 11.5682 & 44.3179 \\
\hline
\end{tabular}


The results showed the highly performance in terms of image quality that converge to the original image that implicitly affected by the error tolerance, with nearly same compression ratio values as in the first stage. The main reason of the improving of image quality in the second stage techniques due to dominating residual difference between the original and compressed one resultant of first stage proposed system.

\section{Conclusions}

From the test results of the proposed system, the following remarks are stimulated:

1- The traditional polynomial coding technique characterized by their simplicity and limited redundancy removal of spatial domain base, but with proposed two stages techniques more reduction occurred with high image quality. Where by the first stage the fixed predictor along with thresholding based utilized efficiently, and in the second stage the near lossless base enhanced the quality obviously.

2- The adaptive polynomial coding is a hybrid technique that exploited the spatial domain and the frequency domain using the fixed predictor, wavelet transform, polynomial coding and soft thresholding technique that leads to improve the performance results.

3- The results clearly shows the better adaptive performance than the traditional polynomial coding, more compression ratio achieved (i.e., two times on average) with higher image quality according to error tolerance $(\delta)$.

\section{Refrences}

1- Rasha, Al-T. 2015. Intra Frame Compression Using Adaptive Polynomial Coding .MSc. thesis, Baghdad University, Collage of Science.

2- Ghadah, Al-K. 2016. Interpolative Absolute Block Truncation Coding for Image Compression. International Journal of Computer Science and Mobile Computing, 5(7), 553-557.

3- Mohammed, M. and Ghadah, Al-K. 2013. Applied Minimized Matrix Size Algorithm on the Transformed Images by DCT and DWT used for Image Compression. International Journal of Computer Applications, 70(15), 33-40.

4- Noor, S. M. 2015. Image Compression based on Adaptive Polynomial Coding. Diploma, Dissertation, Baghdad University, Collage of Science.

5- Sehoon, Y. and William A. 2006. A Wavelet-Based Two Stage Near Lossless Coder. IEEE Transcation Image Processing, 15(11), 1-14.

6- Ghadah, Al-K. 2013. Image Compression based on Quadtree and Polynomial. International Journal of Computer Applications, 76(3),31-37.

6- Babatunde, S. 2015. Development of an Improved Approach to Biometric Fingerprint Image Compression using Coiflet Signal Transformation Algorithm. Ph.D. thesis. Ahmed Bello University, Nigeria. 


$$
\begin{aligned}
& \text { غادة كاظم طعمة شيماء فاضل عباس } \\
& \text { جامعة بغداد / كلية العلوم / قسم علوم الحاسوب }
\end{aligned}
$$

ضغط الصور موضوع ظروري-اساسي لتقليل المساحه الخزنيه و زمن الارسال بالاعتماد على الاستخدام الامثل لمعلومات الصورة المكررة و المطموره بين نقاط الصوره نفسها بالاضافه الى استغلال محدوديه ادر اك الانسان للمعلومات الغير المرئيه.

متعدد الحدود واحدة من طرق ضغط الصور الحديثة والتي تعتمد على مفهوم النمذجة لاز اله التكرارات الحيزيه المطموره بين نقاط الصوره بكفاءهو التي تتالف من جزئين، الجزء الاول هو النموذج الرياضي والجزء الثاني هو مقدار الخطأ. في هذا البحث، الطريقة المستخدمه اعتمدت مرحلتين والتي تبدا باستخدام التوقع الثابت التعددي و التكميم الفقداني والتي تمثل المرحله الاولى متبو عه باستخدام تقنيه الغير فقدان التقريبي لنتيجه المرحله الاولى و التي تمثل المرحله الثانيه. النتائج المستحصله واعده لكلا المرحلتين حيث انها ضمنيا حسنت اداء متعدد الحدود التقليدي بمعنى زيادة نسبة الضغط مع المحافظة على جودة الصورة المضغوطة.

الكلمات المفتاحيه: ضغط الصور، التوقع الثابت، التحول المويجي، متعدد الحدود، تقنيات الغير فقدان التقريبي 